$\triangle 115$

EFFECTS OF DIOXINS AND POLYCHLORINATED BIPHENYLS ON THYROID HORMONE STATUS OF PREGNANT WOMEN AND THEIR INEANTS.

Corine Koopman-Esseboom', Dennis C. Morse², Nynke Weisglas-Kuperus',

'Dep. of Paediatr., Div. Of Neonatol., Erasmus Univ./Sophia Children's Hosp., Rotterdam. 'Dep. of Toxicol, Agricult. Univ., Wageningen. Dioxins and polychlorinated biphenyls (PCBs) are potentially hazardous compounds that can altex the thyroid hormone homeostasis as shown in delivery and in their infants just after delivery at 2 wks and mnths of age. Dioxin and PCB levels were measured in human milk and in maternal and umbilical cord plasma.

\begin{tabular}{|c|c|c|c|c|c|}
\hline & $\begin{array}{l}\text { Women in } \\
\text { pregnancy }\end{array}$ & Women & delivery & $\begin{array}{l}\text { Infant } \\
2 \text { wks }\end{array}$ & $\begin{array}{l}\text { Infant } \\
3 \text { mnths }\end{array}$ \\
\hline $\mathrm{N}=78$ & $\mathrm{TT}_{3}$ & $\mathrm{TI} \mathrm{I}_{3}$ & $\mathrm{TT}_{4}$ & TSH & TSH \\
\hline Dioxins & $-.47^{\circ}$ & $-.35^{*}$ & $-.34^{\circ}$ & $.38^{-\prime}$ & $.41^{m}$ \\
\hline Planax PCBs & $-.39^{\prime \prime}$ & $-.38^{\prime \prime}$ & $-.33^{\circ}$ & $.37^{-}$ & $.31^{\circ}$ \\
\hline $\begin{array}{l}\text { Non-planar } \\
\text { PCBs }\end{array}$ & $-.36^{\circ}$ & $-.33^{\circ}$ & N.S. & $.38^{-\prime}$ & N.S. \\
\hline
\end{tabular}

$\mathrm{TT}_{3}=$ total triiodothyronine, TT $\mathrm{T}_{1}=$ total thyroxine, TSH=thyreotropine.

Conclusions: 1)TT, and $\mathrm{TT}_{\text {, }}$ levels are negatively correlated to $\mathrm{PCB}$ and dioxin levels as can be found in the Dutch population. 2)TSH levels in newborns are significantly elevated at higher PCB and dioxin exposure.

3) These results indicate that PCBs and dioxins as found in the norma
116

MOLECULAR ANALYSIS OF Rb-1 SEGREGATION PATTERN IN FAMILIES OF CHILDRREN WITH RETINOBLASTOMA

Ewa Kostyk, Agnieszka Jasińska, Jerzy Więckiewicz, Helena ZygulskaMept.of Medical Genetics, Dept of Clinical Immunology, Dept. of Dept. of Medical Genetics, Dept. of Clinical Immunology, Dept. of
Ophtalmology, Faculty
Kraków, Institute for Cancer Research Dept.of Genetics Det Norske Radi umhosp. Oslo

The group of 95 retinoblastoma children from all around the Poland was ascertained from 1989 through 1993 by the Dept. of Ophtalmology and Dept. of Medical Genetics, Faculty of Medicine of Jagiellonian University. In this group 11 multiplex families were relatives was performed. Three independent methods were used: 1 . Genetic segregation of $\mathrm{Rb}-1$ locus with specific. RFLP-s as genetic markers, 2. Analysis of XbaI polymorphism in intron 17 of Rb-1 gene using the PCR technique. 3. Analysis of polymorphic Rb 1.20 CTY T/ repeats. Results: All 11 families appeared to be informative by at least one of the above techniques, which made it possible to define the segregation pattern of the mutant allele within the families. The transmission of the mutant $\mathrm{Rb}-1$ allele by affected parent was proved
in 6 families and carrier status among the parents and siblings. in 6 families and carrier status among the parents and siblings without any symptoms of the disease was found in 4 cases. In addition
we were also able to rule out the presence of mutation in 8 cases. Conclusions: By means of these studies the risk prediction of retinoblastoma development for the probands siblings and future offspring is possible. Based on this information, early clinical for the rinal outcome.

\section{$\Delta 118$}

INFLUENCE OF BODY POSITION ON APNEA, HYPOXEMIA AND BRADYKARDIA IN PRETERM INFANTS. W.Krämer, H.Stopfkuchen, R.Lippold*

Methods: 20 preterm infants (mean 28wks; range 24-34wks gestational age, GA) with distinct instability during routine monitoring were studied in prone (PP) and supine (SP) sleeping position. In 45 polygraphic recordings (mean $8,9 \mathrm{hrsPP} / 7,3 \mathrm{hrs} \mathrm{SP}$ ) we analysed 14829 events with regard to conceptional age at time of acquisition (groupI: $\leq 37 \mathrm{wks} /$ group I: $>37 \mathrm{wks}$ ), type and duration of event (central, obstructive, mixed apnea(A.), hypopnea, isolated bradycardia), effect on heart rate and arterial oxygen saturation ( $\mathrm{SaO} 2$ ). Results: In groupI (mean 34wks, range 31 37wks GA) A. density was identical in PP and SP (median: $46,7 \mathrm{~h}$ ). In PP obstructive A. increa sed (PP 40\%/ SP 34\% of all events) and central A. decreased (PP $48 \% / S P 52 \%$ ). Duration, mean heart rate and mean $\mathrm{SaO} 2$ before an event and associated desaturation defined as fall $\geq 3 \%$ of mean $\mathrm{SaO} 2$ were similar. Hypoxemia associated with any type of resp. event was more frequent

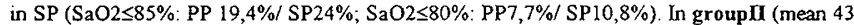
wks; range $38-55$ wks GA) A density was reduced (PP32,8/h; SP34,9/h). Again obstructive A was increased in PP (PP45,3\%/ SP39,2\%), while central A did not reveal disparity (PP46,6\%) SP $46,4 \%$ ). Compared to group I the number of bradycardias and desaturation in association with a respiratory event was lower. However bradycardias mainly ocurred in $\mathrm{SP}(\mathrm{HR} \leq 100 \mathrm{bpm}$ PPI , 4\% / SP 4,0\%; HR $\leq 80 \mathrm{bpm}$ : PP 0\%/SP $1 \%$ ). Desaturation ( $\geq 3 \%$ : PP $26,5 \% / \mathrm{SP} 46,2 \%$ ) and hypoxemia were more frequently noted in SP (SaO2 $58 \%$ : PP $2,4 \%$ / SP $7,3 \% ; \leq 80 \%$ : PP1,4\%/ SP2,9\%). Summary: Positioning influenced the incidence of $A$, hypoxemia and bradycardia. In PP obstructive A were more common $(p=0,06)$. In contrast to other studies we found that hypoxemia $(\mathrm{SaO} 2 \leq 85 \%$ : all events $\mathrm{p}=0,01 ; \mathrm{central} \mathrm{A}, \mathbf{p}=\mathbf{0 , 0 0 1})$ and with increasing conceptional age bradycardias were more frequent in SP. Conclusion: 1 . When positioning unstable preterm infants, consider possible effects on cardiorespiratory regulation. 2.Evaluation of pneumogramms must include the position of the infant. NICU and Statistic. Instit. *. Mainz University, Germany.

\section{7}

ANALYSIS OF OSCILLATORY PRESSURE TRANSIENTS AFTER FLOW INTERRUPTION IN HEALTHY AND ASTHMATIC CHILDREN DURING BRONCHIAL CHALLENGE

Richard Kraemer and Urs Frey. Division of Paediatric Respiratory Medicine, Department of Paediatrics, University of Berne, Inselspital, $\mathrm{CH}-3010$ Berne, Switzertand

Postocclusional oscillatory pressure transients after rapid flow interruption features additional parameters to the end-interruption resistance (Rint $\operatorname{le}$ ). To detect changes in additional parameters to the end-interruption resistance (Rinte日). To detect changes in lung function during bronchial provocation tests in 10 healthy (age: $7-14$ years) and
50 asthmatic children (age: 5 - 15 years) were studied. By such analysis the resonance 50 asthmatic children (age: $5-15$ years) were studied. By such analysis the resonance
frequency $\omega_{0}$, the damping factor d (time series), the resonance frequency $F_{F S}$ and the frequency $\omega_{0}$, the damping factor $\underline{d}$ (time series), the resonance frequency $F_{F S}$ and the
amplitude at $F_{F S}$, the power factor $A_{F S}$ (frequency series), can be obtained. Cumulative amplitude at $\mathrm{F}_{F S}$, the power factor $\mathrm{A}_{\mathrm{FS}}$ (frequency scries), can be obtained. Cumulative
doses of inhaled carbachol $(125,250,500,750,1000 \mu \mathrm{g})$ were administered and the doses of inhaled carbachol $(125,250,500,750,1000 \mu \mathrm{g})$ were administered and variance-based provocation dose $\left(\mathrm{PD}_{\mathrm{vb}}\right)$ for $\omega_{0}, \mathrm{~d}, \mathrm{~F}_{\mathrm{FS}}$, $\mathrm{A}_{\mathrm{FS}}$ and Rint $\mathrm{El}$ were calculated. Significant mean changes during bronchial chalienge were obtained for Rint $_{\mathrm{F}} 10.6 \pm 12.5 \mathrm{SD}(53 \%)$ in healthy, $7.5 \pm 9.7 \mathrm{SD}(54 \%)$ in asthmatics,
$\underline{\mathrm{d}} 7.2 \pm 9.4 \mathrm{SD}(53 \%)$ in healthy, $6.7 \pm 7.1 \mathrm{SD}(45 \%)$ in asthmatic children respectively. With respect to sensitivity and spocificity $d$ was the most sensitive and specific parameter represented by a $\mathrm{PD}_{\mathrm{yb}}$ at a lower threshold $(68 \%$ at $345 \mu \mathrm{g})$ than Rint $_{\mathrm{F}}(62 \%$ at $708 \mu \mathrm{g}$ ) for carbachol. Moreover, reversibility after $800 \mu \mathrm{g} \mathrm{salbutamo}$ was better reflected by $\mathrm{d}(7.5 \mathrm{SD}: \mathrm{p}<0.00 \mathrm{l})$ than by Rinte (3.0 SD). Analysis of postocclusional pressure transients af ter flow interruption could be a better estimate of postocclusional pressure transicnts af ter flow interruption could be a better estir conducting properties of the airway and the inductive element given by the volume

\section{$\Delta 119$}

HIGH FREQUENCY OF CLASSICAL 21-HYDROXYLASE DEFICIENCY (CAH) IN MALAYSIA. LOO L hU, Gabi Krob*, Janine Pekarak*, Ben $S$ Hasri, Ursula Kuhnle. Department of Pediatrics, Universiti Kebangsaan Malaysia, Kuala Lumpur, Malaysia, and *Universitaetskinderklinik, Muenchen, Germany

Neonatal screening programs in caucasian populations of Europe, North America, New Zealand as well as in Japan have established the incidence of $\mathrm{CAH}$ to be on an average $1: 14,000$, with few exceptions (native Alaskan and inhabitants of the island Le Reunion), where a founder effect and a relative isolation has contributed to a higher incidence. So far no evaluation of $\mathrm{CAH}$ in a tropical country is available.

We have performed a case survey in Kuala Lumpur (KL) using the birth rate of the Maternity Hospital- and the patients referred to the Pediatric Endocrine Unit of the General Hospital, KL. The overall incidence rate was $1: 3,000$ with appr. equal distribution among the Malay, Chinese and Indian populations, comprising 57, 168, and 13:, respectively. This unexpected high incidence of a potentially salt-wasting disorder in a tropical country can only partially be explained by consanguinity which is frequent in the Malay- and Indian-, but not in the chinese community. An as of yet unknown, selective advantage of the heterozygote state has to be speculated.

\section{0}

THE DIAGNOSIS OF PAEDIATRIC VOCAL CORD DYSFUNCTION (VCD). Gideon Lack", Florence B. Blager, Susan M. Brugman, Janet H. Howell, Leeland Fan, Institute of Child Health", University of Bristol,
U.K., and Department of Pediatrics, National Jewish Center for Immunology and Respiratory Medicine, Denver, Co,

VCD in children is a poorly recognised entity, easily confused with asthma. Thirty-seven children with a diagnosis of VCD made by with both VCD and asthma were evaluated during attacks of VCD (defined by rhinolaryngoscopy) or asthma (defined by a positive clinical assessment, spirometry and blood gas analysis in differentiating between episodes of VCD and asthma in these
patients. Laryngeal stridor was the most reliable clinical feature patients. Laryngeal stridor was the most reliable clinical feature
that distinguished VCD from asthma, occurring in $6 / 8$ episodes of expira $1 / 8$ episodes of asthma. The presence or localisation of expiratory wheezing was not helpful. Spirometric data did not truncation occurred during $4 / 8$ episodes of VCD and not during. asthma. The mean arterial oxygen level, though lower in asthma than in VCD, did not reliably differentiate between both conditions. However, the calculated alveolar-arterial (A-a)
gradient was narrow during all episodes of vCD (mean $=6.75 \mathrm{~mm} \mathrm{Hg}$ ) whereas it was widened during all episodes of asthma mean $=20.3 \mathrm{~mm}$ coexists with asthma. Episodes of vCD and asthma are not reliably distinguished in children by clinical and spirometric evaluation. Rhinolaryngoscopy is therefore necessary to establish a diagnosis of VCD. Subsequent episodes of VCD may be reliably distinguished from asthma by a normal A-a gradient. 